\title{
ESTIMATIVA DO NÚMERO DE POSSÍVEIS DOADORES DE ÓRGÃOS NO ESTADO DE SERGIPE NO ANO DE 2007
}

\author{
Estimation of the Amount of possible organ donors in Sergipe/Brazil in 2007
}

Thais Kuhn Rodrigues; Antônio Alves Júnior

\begin{abstract}
RESUMO
O transplante é a melhor opção de tratamento para a doença terminal de alguns órgãos e a única opção para interferir na evolução natural de alguns tipos de insuficiência. Porém, a principal fonte de órgãos para transplante é o doador falecido e esse número é insuficiente para atender a demanda, por falhas em diversas etapas do processo doação-transplante. Objetivos: Estimar o número de possíveis doadores de órgãos e tecidos no estado de Sergipe, identificar o perfil desses possíveis doadores, calcular as taxas de doação, notificação e aproveitamento de doadores de órgãos no estado. Métodos: Estudo quantitativo, descritivo e retrospectivo, utilizando dados coletados nos laudos necroscópicos do Instituto Médico Legal de Sergipe e nos prontuários de pacientes notificados à Central de Transplantes do Estado no mesmo período. Resultados: Foram analisados 1388 laudos necroscópicos referentes aos óbitos ocorridos entre $1^{\circ}$ de janeiro e 31 de dezembro de 2007 , dos quais se destacaram $128(9,22 \%)$ possíveis doadores; destes, $108(84,4 \%)$ eram do sexo masculino. A média de idade foi de 30,95 anos e a faixa etária predominante foi de 21 a 40 anos, com 54,4\% dos indivíduos. As vítimas foram em sua maioria (86\%) atendidas no Hospital de Urgências de Sergipe, referência em trauma no estado e a causa de óbito foi acidente de trânsito em 78 casos (60,94\%). Nesse período, houve 89 notificações à Central de Transplantes, tendo sido 28 por morte encefálica e tendo havido correspondência entre os dados do IML e da CNCDO/SE em apenas 22 casos. Foram efetivadas 50 doações, das quais apenas 41 foram de córneas, oito de córneas e rins e uma de múltiplos órgãos. O índice de notificação foi 1:5,82; a taxa de aproveitamento das notificações foi de 56,18\%; a taxa de notificação foi 0,46 pmp e a taxa de doação 0,26 pmp. Conclusão: Houve baixa taxa de notificação e baixo aproveitamento do número de potenciais doadores e, portanto, são necessárias medidas que envolvam todas as esferas da sociedade, com o objetivo comum de aumentar a doação e os transplantes em Sergipe.
\end{abstract}

Descritores: Doação de Órgão; Transplantes; Traumatismos Encefálicos.

\section{Instituição:}

Departamento de Medicina do Hospital Universitário da Universidade Federal de Sergipe Aracaju, Sergipe, Brasil.

\section{Correspondência:}

Thais Kuhn Rodrigues

Rua João Santana, 215 - bloco A, ap. 204 - CEP 49025-480 - Aracaju-SE, Brasil

Tel.: (79) 3217-7309

E-mail: thaiskuhnrodrigues@yahoo.com.br

Recebido em: 10.08 .2010

Aceito em: 29.09.2010

\section{INTRODUÇÃO}

A importância dos transplantes é indubitável para pacientes com insuficiência renal crônica, por apresentarem resultados superiores à diálise ${ }^{1-4}$ e menor custo social. Para os hepatopatas, cardiopatas e pneumopatas terminais, passa a ser de maior importância, pois nesse caso o transplante é a única opção para adiar a morte certa que sobreviria em poucos meses. ${ }^{5}$

"A história dos transplantes é um dos capítulos de maior êxito na história da Medicina, tendo evoluído de um procedimento muito arriscado, realizado apenas em casos de doença renal grave para uma terapêutica eficaz em pacientes terminais de coração, fígado e pulmão num período inferior a três décadas". ${ }^{5}$

No Brasil, o primeiro transplante de órgão sólido (rim) bem sucedido foi realizado em $1965^{6}$ e o primeiro transplante cardíaco foi realizado em 1968 por Zerbini. ${ }^{7,8}$ Atualmente, cerca de 3200 transplantes renais são realizados anualmente. ${ }^{9}$ Para o sucesso alcançado, contribuíram os avanços nas técnicas cirúrgicas e nos cuidados intensivos, o aprimoramento das soluções de preservação de órgãos e, em particular, a introdução de drogas imunossupressoras mais modernas e com menos efeitos deletérios. 
Em conjunto, tais medidas levaram a uma significativa melhora nos resultados dos transplantes de rim, coração, pulmão e fígado, de modo que os pacientes alcançaram sobrevida de $80 \%$ em dois anos. ${ }^{10} \mathrm{E}$ foram justamente esses melhores resultados que tornaram a indicação de transplante de órgãos sólidos cada vez mais liberais, englobando idosos e pacientes com doenças sistêmicas associadas ${ }^{11}$ o que, por outro lado, contribuiu para acentuar a disparidade entre a pequena oferta de órgãos e a grande necessidade de transplantes. O processo doação-transplante, no entanto, é bastante complexo, ${ }^{12-14}$ passando por várias etapas, desde a identificação do potencial doador, sua notificação, manutenção e abordagem à família, antes de chegar ao procedimento de retirada dos órgãos e implante no receptor. ${ }^{14}$ Cada uma dessas etapas apresenta suas particularidades e dificuldades inerentes e, permeando todas elas, há os aspectos bioéticos e legais. ${ }^{15}$

Com relação à regulamentação dos transplantes no Brasil, em 1997 foi criada a chamada Lei dos Transplantes (Lei $n^{\circ}$ 9.434, de 4 de fevereiro de 1997) ${ }^{16}$ e o Decreto $n^{\circ} 2.268$, de 30 de junho de 1997 que a regulamentou e criou o Sistema Nacional de Transplantes (SNT).17 O transplante com doador vivo é também regulado pelo Estado, que financia mais de $95 \%$ dos transplantes realizados no Brasil, além de subsidiar os medicamentos imunossupressores para todos os pacientes. ${ }^{18} \mathrm{O}$ processo de doação e transplante depende também do reconhecimento da morte encefálica, de acordo com o protocolo do Conselho Federal de Medicina (CFM). ${ }^{19}$

O Brasil possui hoje um dos maiores programas públicos de transplante de órgãos e tecidos do mundo. Com 548 estabelecimentos de saúde e 1376 equipes médicas autorizados a realizar transplantes, o Sistema Nacional de Transplantes está presente em 25 estados do país por meio das Centrais Estaduais de Transplantes. ${ }^{20}$

O bom desempenho alcançado pelo Brasil fica evidente quando se verifica que ele é o segundo país em número absoluto de transplantes renais no mundo, perdendo apenas para os Estados Unidos. Em relação aos outros órgãos, o número de transplantes de fígado e pâncreas vem crescendo entre $20 \%$ e $30 \%$ ao ano. Exceção ocorre com relação aos transplantes cardíacos, que cresce em menores proporções. ${ }^{18}$

Apesar disso, a captação de órgãos com finalidade de transplante é bem menor no Brasil, quando comparada com outros países ${ }^{21}$ (em especial a Espanha, com seus excelentes índices), ${ }^{22}$ sendo incapaz de suprir as necessidades da população, como se pode perceber pelas crescentes listas de espera por órgãos. ${ }^{9,20}$

Vários são os fatores apontados para impedir o incremento dos transplantes, principalmente na rede pública de saúde. Segundo Marinho, são oito os limitadores da expansão do número de transplantes no SUS: 1) problemas de compatibilidade e incentivos à doação; 2) número limitado de doações a partir de mortos; 3) limitação de doação entre vivos; 4) tamanho (estrutura) dos hospitais; 5) deterioração dos órgãos e expansão da demanda; 6) taxa de mortalidade nas filas; 7) discriminação das minorias e 8) administração e gerência das filas. ${ }^{23}$

Outro grande entrave à doação de órgãos é a subnotificação dos potenciais doadores às CNCDOs. ${ }^{24-26} \mathrm{Na}$ tentativa de minimizar a disparidade entre a necessidade e a disponibilidade de órgãos, algumas atitudes acenam no sentido de aumentar a oferta de órgãos, como a inclusão de doadores ditos "estendidos", pelo fato de não se enquadrarem nos critérios de "doadores ideais". ${ }^{27}$
Também nessa direção há o aprimoramento no cuidado ao potencial doador, reduzindo tanto quanto possível os efeitos deletérios que a síndrome inflamatória da morte encefálica produz sobre os órgãos que poderão vir a ser doados, através do manejo hemodinâmico, laboratorial e hormonal mais rigoroso. ${ }^{28,29}$

Para tentar superar a grande dificuldade que é a obtenção de órgãos de doadores falecidos, estão sendo pesquisadas fontes alternativas de órgãos. Já se estuda o xenotransplante ${ }^{30}$ (transplante entre espécies) e a utilização de células-tronco, ${ }^{31}$ mas os resultados ainda estão aquém do esperado, de modo que o melhor caminho parece ser intervir positivamente em cada uma das complexas etapas do processo doação-transplante. Para tanto, é necessário conhecer profundamente a problemática que envolve cada uma dessas etapas para poder apontar caminhos no intuito de corrigir as possíveis falhas e obter, ao final, melhores resultados.

Considerando a importância da doação de órgãos para a sociedade, essa pesquisa tem como objetivos:

- Estimar o número de possíveis doadores de órgãos e tecidos no Estado de Sergipe;

- Identificar o perfil dos possíveis doadores de órgãos em Sergipe;

- Calcular as taxas de doação, de notificação e o aproveitamento de doadores de órgãos no Estado.

\section{MÉTODO}

Trata-se de um estudo de caráter quantitativo, descritivo e retrospectivo. ${ }^{32}$

Para sua elaboração foram analisados retrospectivamente os laudos necroscópicos no Instituto Médico Legal de Sergipe (IML/ $\mathrm{SE})$, referentes aos óbitos ocorridos no período de $1^{\circ}$ de janeiro a 31 de dezembro de 2007. Para otimizar a coleta desses dados foi elaborado um protocolo no qual constavam os critérios de inclusão e exclusão e ainda aspectos demográficos (idade, etnia, sexo) e epidemiológicos (local da ocorrência, data e hora da internação, causa e hora do óbito).

Para os cálculos de taxas e índices de notificação, doação e aproveitamento das notificações, foi obtido o número de notificações e de doações no período na Central de Notificação, Captação e Distribuição de Órgãos de Sergipe (CNCDO/SE), onde também foram analisados os prontuários dos possíveis doadores de órgãos que foram notificados, onde se encontravam pacientes em morte encefálica por traumatismo crânio-encefálico (TCE). De forma semelhante, utilizou-se um protocolo para coleta desses dados onde, além dos aspectos demográficos e epidemiológicos, constavam informações acerca do tipo de notificação (busca ativa versus passiva) e causa da não efetivação da doação, quando esse fosse o caso.

Todas as informações foram coletadas após prévia autorização pelas instituições participantes e do projeto ter sido enviado ao Comitê de Ética e Pesquisa da Universidade Federal de Sergipe (CAAE 0068.0.107.000-10).

Os critérios de inclusão utilizados para considerar um possível doador de órgãos na casuística deste trabalho foram:

- Idade máxima de 65 anos;

- Indivíduos com óbito relacionado a TCE;

- Pacientes que receberam atendimento hospitalar antes do corpo 
ser encaminhado ao IML para necropsia;

- Pacientes que tivessem registro de morte encefálica por TCE nos arquivos do IML/SE e/ou CNCDO/SE, no período estudado.

Foram excluídos indivíduos que apresentavam algum dos seguintes critérios:

- Pacientes que, além do TCE, apresentassem lesões descritas na região tóraco-abdominal;

- Potenciais doadores cuja causa de morte tenha sido um evento não traumático, como acidente vascular cerebral (AVC) ou neoplasias primárias do sistema nervoso central;

- Presença de infecções associadas, tais como pneumonia, meningite ou sepse;

- Pacientes com sorologia positiva para patologias como Síndrome da imunodeficiência adquirida, hepatites, sífilis e infecções por HTLV I e II;

- Pacientes com neoplasias associadas,

Os resultados de idade e tempo de internamento são fornecidos na forma de média e desvio-padrão. A análise estatística foi executada pelo teste de qui-quadrado nas variáveis: faixa etária, motivos do óbito e mês do óbito. Resultados foram considerados significantes quando $\mathrm{p}<0,05$.

\section{RESULTADOS}

Foram analisados 1388 laudos necroscópicos referentes ao ano de 2007 no Instituto Médico Legal de Sergipe, dos quais 128 (9,22\%) foram considerados possíveis doadores, sendo 108 (84,4\%) do sexo masculino e $20(15,6 \%)$ do sexo feminino. A média de idade foi 30,95 anos, com desvio padrão de 14,424 numa faixa etária até 65 anos (Tabela 1).

Tabela 1 - Dados sobre idade, tempo de internamento e sexo dos potenciais doadores obtidos no IML/SE.

\begin{tabular}{|l|l|l|l|}
\hline Dados 2007 & Idade (anos) & $\Delta \mathrm{T}$ (minutos) & Sexo \\
\hline Mínimo & 1 & 1440 & M: $108(84,4 \%)$ \\
\hline Máximo & 65 & 41550 & F: $20(15,6 \%)$ \\
\hline Mediana & 28,00 & 7526,00 & \\
\hline Média & 30,95 & 8783,16 & \\
\hline Desvio padrão & 14,424 & 7179,12 & \\
\hline
\end{tabular}

M: Masculino; F: Feminino; $\Delta T$ : Tempo de internamento.

Em relação à distribuição por faixa etária, tem-se que 68 deles $(54,4 \%)$ encontravam-se na faixa entre 21 e 40 anos, valor que não foi estatisticamente significante $(p=0,289)$. Na faixa de um a 20 anos localizavam-se $22,4 \%$ dos indivíduos (Figura 1).
Figura 1 - Representação gráfica da distribuição dos possíveis doadores de órgãos por faixa etária.

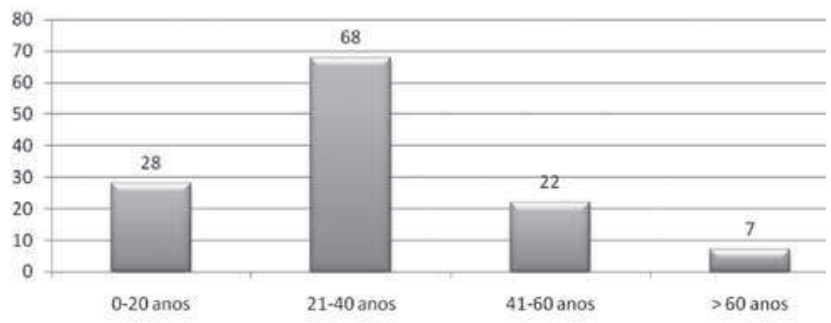

Do total dos potenciais doadores, $108(86,4 \%)$ foram admitidos no Hospital de Urgências de Sergipe (HUSE) antes do óbito, hospital que é referência em trauma no Estado. O tempo médio de internamento foi de 8783,16 minutos (equivalente a 6 dias), sendo o tempo mínimo de 1440 minutos e o máximo de 41550 minutos (28,8 dias), conforme demonstrado na Tabela 1. Em relação ao turno do óbito, tem-se que 62 deles (53\%) ocorreram durante o plantão diurno (7 às $19 \mathrm{~h}$ ) e, destes, seis efetivaram-se doadores, e 55 óbitos (47\%) ocorreram durante o plantão noturno, não havendo nenhum doador dentre eles. Houve diferença estatisticamente significante $(\mathrm{p}=0,18)$.

Com relação ao quadro clínico na admissão hospitalar, observouse que a maioria $(n=74 ; 62,71 \%)$ foi admitida em coma. Trinta e cinco $(29,67 \%)$ estavam inconscientes e apenas nove pacientes $(7,63 \%)$ chegaram ao hospital ainda conscientes (Figura 2).

Figura 2 - Representação gráfica do quadro clínico em que os indivíduos chegaram ao hospital.

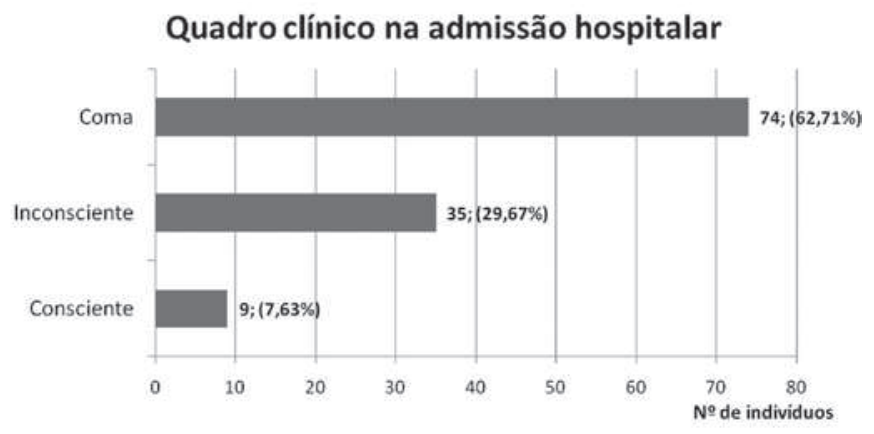

Outras lesões além de TCE estavam presentes em 29 indivíduos (22,66\%), sendo que destes, 22 (17,19\%) eram politraumatizados. Entre as causas do óbito, acidentes de trânsito foram responsáveis por $78(60,94 \%)$ mortes, seguidos pelos homicídios, que vitimaram 27 pessoas $(21,09 \%)$ e quedas, responsáveis por 19 óbitos $(14,84 \%)$. Considerando apenas os homicídios, armas de fogo foram a causa em $15(11,72 \%)$ das mortes, armas brancas foram usadas em dois $(1,56 \%)$ e espancamento foi responsável por 10 (7,81\%) óbitos. A causa "suicídio" foi incluída em "outros", que totalizaram quatro óbitos (3,13\%) (Figura 3). 
Figura 3 - Representação gráfica das causas de óbito encontradas nesta casuística.

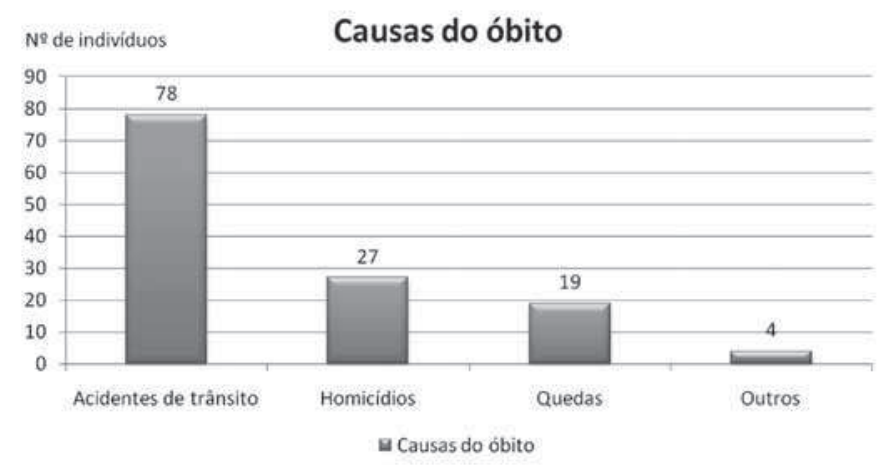

Em relação ao período, observou-se que os óbitos foram uniformemente distribuídos ao longo do ano, como pode se observar na figura 4.

Figura 4. Representação esquemática do período de 2007 em que ocorreu o óbito.

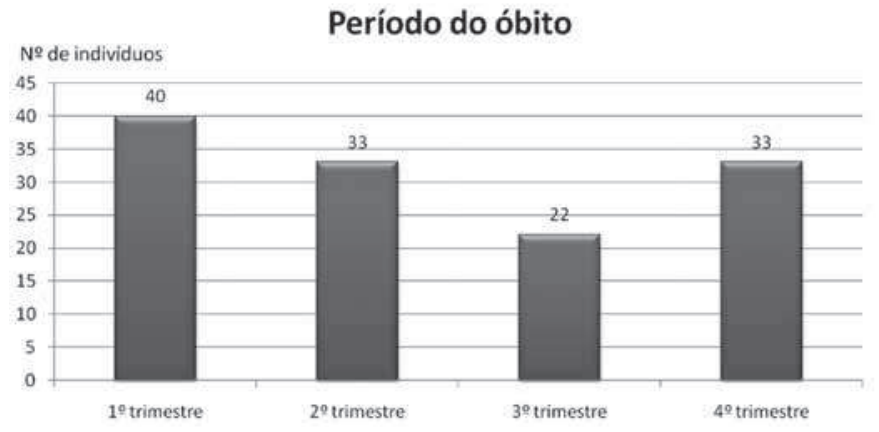

Dessa população de 128 possíveis doadores observados no IML/ $\mathrm{SE}$, apenas $22(17,19 \%)$ casos foram notificados à $\mathrm{CNCDO} / \mathrm{SE}$; destes 22 , apenas seis $(27,27 \%)$ efetivaram-se como doadores de órgãos, enquanto que em 18 casos notificados, por motivos diversos, a doação não foi efetivada.

O perfil desses possíveis doadores notificados pode ser observado na Tabela 2.

Tabela 2 - Dados sobre idade, tempo de internamento e sexo dos potenciais doadores notificados à CNCDO/SE.

\begin{tabular}{|l|l|l|l|l|}
\hline Dados 2007 & Idade (anos) & $\begin{array}{l}\Delta \mathrm{T} \\
\text { (minutos) }\end{array}$ & Sexo & Etnia \\
\hline Mínimo & 14 & 2099 & $\begin{array}{l}\text { M: } 18 \\
(81,81 \%)\end{array}$ & B: 6 \\
\hline Máximo & 49 & 18210 & $\begin{array}{l}\mathrm{F}: 4 \\
(18,18 \%)\end{array}$ & $\mathrm{N}: 2$ \\
\hline Mediana & 23,5 & 4914 & & $\mathrm{P}: 5$ \\
\hline Média & 26,04 & 7533,18 & $\begin{array}{l}\text { sem } \\
\text { dados:9 }\end{array}$ \\
\hline $\begin{array}{l}\text { Desvio } \\
\text { padrão }\end{array}$ & 9,26 & 5591,77 & & \\
\hline
\end{tabular}

M: Masculino; F: Feminino; $\Delta T$ : Tempo de internamento; $B$ : Brancos; N: Negros; P: Pardos
Nesse mesmo ano, foram realizadas 89 notificações à Central de Transplantes de Sergipe, sendo 61 por parada cardiorrespiratória (PCR) e 28 decorrentes de morte encefálica por diversas etiologias. Das 89 notificações, foram efetivadas 50 doações, das quais 41 foram de apenas córneas, oito de córneas e também rins e um caso de múltiplos órgãos. Nesse caso, foram aproveitados para doação fígado, rins e córneas.

Considerando a população do Estado no referido ano de 1.939.426 habitantes, segundo o Instituto Brasileiro de Geografia e Estatística (IBGE) e o total de óbitos em 2007 igual a 9632, de acordo com a Secretaria Estadual de Saúde (SES/SE), as taxas e índices podem ser observados na Tabela 3 .

Tabela 3 - Taxas e índices de notificação e de doação

\begin{tabular}{|l|l|}
\hline Taxa ou índice & Valor \\
\hline Índice de notificação & $1: 5,82$ \\
\hline Taxa de aproveitamento das notificações & $56,17 \%$ \\
\hline Taxa de notificação & 0,46 pmp/ano \\
\hline Taxa de doação & 0,26 pmp/ano \\
\hline Pmp: por milhão de população. & \\
\hline
\end{tabular}

Por fim, em relação ao tipo de busca de doadores, observou-se que em $31,42 \%$ casos com registro houve busca ativa por parte dos funcionários da $\mathrm{CNCDO} / \mathrm{SE}$, e em $62,58 \%$ houve busca passiva, seja através de notificações do próprio hospital onde ocorreu o óbito ou doação espontânea, por iniciativa da própria família, em alguns casos.

\section{DISCUSSÃO}

O fato de o transplante ter se tornado uma terapêutica altamente eficaz na insuficiência terminal de alguns órgãos, ${ }^{10}$ quando não a única alternativa de sobrevivência, fez com que "o transplante se tornasse vítima do seu próprio sucesso", 5 pois pode ser observado um crescente distanciamento entre a demanda para transplante e a disponibilidade de órgãos para tal fim.

Muitos são os fatores que se somam para culminar nesse pequeno número de órgãos e tecidos disponíveis para transplantes. De início, sabe-se que apenas 1 a $4 \%$ dos pacientes de um hospital geral apresentam quadro clínico compatível com morte encefálica, de acordo com os critérios estabelecidos pelo CFM. ${ }^{18}$ Quando são considerados apenas os que vão a óbito em unidades de terapia intensiva, esse índice gira em torno de 10 a $15 \% .^{5}$

Além dos fatores já citados, somam-se outros, como é o caso da dificuldade que muitos médicos possuem em diagnosticar a morte encefálica, inclusive entre intensivistas, que mais se deparam com essa situação. Estudo realizado demonstrou que a prevalência de desconhecimento do conceito de morte encefálica entre eles pode chegar a $17 \% .^{33}$ Tais achados demonstram a necessidade de melhor preparo por parte dos profissionais envolvidos no que concerne ao diagnóstico e aspectos legais da morte encefálica.

Além disso, sabe-se que apenas uma parcela dos possíveis doadores 
converte-se em doadores efetivos por diversos motivos, como contra-indicação médica, instabilidade hemodinâmica, parada cardiorrespiratória irreversível e a recusa familiar. ${ }^{33}$

Os motivos mais frequentes de recusa familiar para doação de órgãos e tecidos para transplante são: (1) desconhecimento do diagnóstico de morte encefálica; (2) desconhecimento do desejo do falecido; (3) inadequação da entrevista familiar na solicitação da doação; (4) problemas com a integridade ou imagem do corpo após a extração dos órgãos e tecidos; (5) questões religiosas; e (6) recusa em vida por parte do falecido. ${ }^{14}$

A subnotificação dos possíveis doadores às instituições competentes é outra realidade observada e os motivos apontados para tal vão desde o não-conhecimento da obrigatoriedade de comunicar a existência de pacientes em morte encefálica ou o desinteresse em fazê-lo, ${ }^{34}$ até o esquecimento e sobrecarga de trabalho, referidos pelos enfermeiros responsáveis pela notificação. ${ }^{35}$

Sabendo que em Sergipe a realidade nacional se repete, havendo doadores insuficientes para atender às necessidades de transplante, este trabalho foi realizado com o intuito de ser instrumento útil na avaliação da realidade local.

Essa pesquisa foi realizada através de laudos necroscópicos obtidos no IML/SE, por onde devem obrigatoriamente passar todas as vítimas de óbitos por causas externas, tendo sido obtido que, dos 1388 laudos necroscópicos analisados, 128 (9,22\%) foram considerados possíveis doadores. Alguns autores sugerem que esses levantamentos sejam realizados em unidades de terapia intensiva ou hospitais de referência em urgência e trauma, mas, visto que os prontuários médicos não são padronizados e muitas vezes encontram-se incompletos, esses dados poderiam ser subestimados. Além disso, observa-se que muitas vezes a morte encefálica não é diagnosticada por profissionais de Saúde. ${ }^{36}$ Por outro lado, permitiria incluir os potenciais doadores cuja morte encefálica não foi devida à TCE, e sim à $\mathrm{AVE}$, tumor primário do sistema nervoso central (na ausência de metástases), crises convulsivas, encefalopatia e outras, que, em algumas casuísticas, já superam as causas traumáticas. Em estudo conduzido numa Organização de Procura de Órgãos (OPO) do Estado de São Paulo, o AVE como causa de morte encefálica foi responsável por $53,48 \%$ dos casos, enquanto o TCE foi responsável por $32,09 \%$ deles. ${ }^{37}$ Levantamento realizado num hospital de urgências de Sergipe entre 2005 e 2007, no entanto, ainda apontava o TCE como principal causa de morte encefálica, ${ }^{25}$ talvez pelo perfil do hospital em que foi realizada a pesquisa.

No entanto, é necessário que a atenção primária à saúde não seja menosprezada, uma vez que certas condições como hipertensão arterial e diabetes são grandes causas de lesão terminal de órgãos e, portanto, causas de transplantes.

Esta pesquisa, que considerou apenas a morte encefálica decorrente de TCE indicou que as principais causas de óbito foram os acidentes de trânsito, responsáveis por 78 (60,94\%) mortes, seguidos pelos homicídios, que vitimaram 27 pessoas $(21,09 \%)$ e as quedas, responsáveis por $19(14,84 \%)$ óbitos. Considerando-se apenas os homicídios, armas de fogo foram a causa de 15 mortes $(11,72 \%)$, e espancamento foi a causa de 10 óbitos (7,81\%). Tais dados estão em consonância com a literatura nacional. Estudo levado a efeito entre 2004 e 2005 pela OPO da Faculdade de Medicina da Universidade de São Paulo (FMUSP) encontrou que acidentes de trânsito foram responsáveis por $44,45 \%$ dos óbitos, havendo apenas uma inversão nas causas que ocuparam o segundo e terceiro lugares nas duas casuísticas. Nesta, a segunda causa foi ocupada por homicídios (de qualquer natureza) e naquela por queda acidental, responsável por 27,27\% dos óbitos; homicídios (ferimentos por arma de fogo e agressão física) representaram a terceira causa, com $24,75 \%$ dos óbitos. ${ }^{38}$

Pesquisa realizada em outra capital do Nordeste com metodologia semelhante à aqui utilizada, encontrou acidentes de trânsito como a causa de $60,3 \%$ dos óbitos, seguida por homicídios, com $24,5 \%$ e queda acidental com $11,3 \%$ dos óbitos. ${ }^{34}$

Em relação ao sexo dos potenciais doadores, $108(84,4 \%)$ deles eram do sexo masculino e $20(15,6 \%)$ do sexo feminino e a média de idade foi de 30,95 anos. Esse perfil do potencial doador como indivíduo jovem, do sexo masculino, que morre principalmente em decorrência de TCE, reflete os perfis encontrados em outras casuísticas tanto a nível nacional como mundial ${ }^{13,24-26,34}$ e provavelmente a maior exposição desses indivíduos a situações de risco. Quando se consideram indivíduos cuja morte encefálica tenha sido devida à AVE e a outras causas naturais, pode-se observar a prevalência do sexo feminino e uma média de idade mais elevada, provavelmente por tratar-se da população mais acometida por tais agravos. ${ }^{37}$

Em relação à distribuição por faixa etária, tem-se que 68 deles $(54,4 \%)$ encontravam-se na faixa dos 21 aos 40 anos, enquanto na faixa de um a 20 anos localizavam-se $22,4 \%$ dos indivíduos. Essa mesma predominância foi observada em outra casuística de Sergipe referente ao ano de 2002. ${ }^{26}$ Estudo realizado em São Paulo, considerando apenas vítimas de trauma, demonstrou que 47,48\% dos indivíduos tinham entre 0 e 25 anos e 33,33\% deles tinham entre 26 e 45 anos; não foi possível realizar uma comparação entre esses dados, visto que o ponto de corte das faixas etárias não é o mesmo. ${ }^{38}$ Com relação ao quadro clínico na admissão hospitalar, observouse que a maioria $(n=74 ; 62,71 \%)$ foi admitida em coma, o que era esperado, pois se tratava de pacientes vítimas de trauma. Outras lesões além do TCE estavam presentes em 29 indivíduos (22,66\%), sendo que destes, 22 (17,19\% do total) eram politraumatizados, porém sem lesões descritas em tórax ou abdome que pudessem ser consideradas como critérios de exclusão.

Em relação ao período em que os óbitos ocorreram, foi observado que eles foram uniformemente distribuídos ao longo do ano, com discreta predominância no primeiro trimestre. Tal achado pode ser justificado pelo fato de tratar-se de um período que engloba férias, o feriado do Carnaval e época de uma tradicional festa local de grandes proporções e, infelizmente, não isenta de vítimas.

Do total de possíveis doadores, $108(86,4 \%)$ foram admitidos no Hospital de Urgências de Sergipe (HUSE) antes do óbito, enquanto que os demais foram atendidos em outros hospitais da capital ou do interior do Estado. Essa grande proporção de atendimentos nesse mesmo hospital já era esperada e condizente com estudos anteriores, ${ }^{26}$ pois se trata de hospital referência em trauma no Estado.

O tempo médio de internamento foi de 8783,16 minutos (equivalente a seis dias), sendo o mínimo de 1440 minutos e o máximo de 41550 minutos (28,8 dias). A média do tempo de internamento foi superior ao intervalo mínimo de seis horas necessário para o diagnóstico clínico de morte encefálica, de acordo com o protocolo do CFM ${ }^{18}$, portanto, o excesso de tempo e não a sua falta poderia ser considerada como justificativa para a não notificação.

Desses 128 potenciais doadores detectados, apenas em 22 casos $(17,19 \%)$ houve correspondência com os dados levantados na Central Estadual de Transplantes e apenas seis tornaram-se 
doadores efetivos. Esse baixo índice de notificação em Sergipe já havia sido demonstrado anteriormente ${ }^{26}$ e também ocorre em outros estados brasileiros. ${ }^{9}$ Apesar de baixo, o índice de detecção de potenciais doadores (e, consequentemente de doadores efetivos) encontrado no Maranhão é inferior ao de Sergipe. ${ }^{34}$ Tal fato demonstra que a sub-notificação é um problema de nível nacional que precisa ser corrigido. Talvez o melhor método para conseguir tal objetivo seja investir na atualização dos profissionais de Saúde, para que conheçam os aspectos legais que envolvem o assunto, como a questão da obrigatoriedade, e para que reconheçam a importância da notificação para o sucesso de todo o processo.

Em relação aos dados levantados na Central Estadual de Transplantes, tem-se que no ano de 2007 houve 89 notificações de possíveis doadores de órgãos e tecidos, sendo que 61 delas eram devidas a óbitos por parada cardiorrespiratória (PCR) e 28 eram decorrentes de morte encefálica por diversas etiologias. Em relação ao tipo de busca dos doadores, observou-se que em $31,42 \%$ dos casos com registro houve busca ativa por parte dos funcionários da $\mathrm{CNCDO} / \mathrm{SE}$, e em $62,58 \%$ houve busca passiva.

Com relação à população do estado no referido ano $(1.939 .426$ habitantes), verificou-se uma taxa de 0,46 notificações/milhão de população (0,46 pmp/ano) e de 0,26 doações/milhão de população (0,26 pmp/ano), valores bem abaixo do necessário para atender às necessidades de transplantes.

Observa-se que houve baixas taxas de notificação, aproveitamento e doações efetivas, demonstrando a necessidade urgente de intervenções no sentido de aumentar a disponibilidade de órgãos para transplante.

Toda ação no sentido de procurar aumentar o aproveitamento dos potenciais doadores deve, portanto, ser empreendida. Deve-se buscar conscientizar os profissionais de saúde sobre a importância da notificação do potencial doador; treiná-los para que seja feito o diagnóstico de morte encefálica, o manejo adequado do potencial doador e uma boa abordagem da família do paciente; investir em campanhas para esclarecimento da sociedade, principalmente sobre o conceito de morte encefálica, na tentativa de reduzir a recusa familiar e investir em hospitais e centrais de transplantes, para permitir a operacionalização efetiva de todo o processo.

\section{CONCLUSÃO}

Baseando-se nos resultados deste trabalho, pode-se concluir que o número estimado de potenciais doadores de órgãos no Estado de Sergipe em 2007 foi de 128 casos, sendo que o perfil do possível doador do Estado foi um indivíduo do sexo masculino, adulto jovem, cuja principal causa de óbito foi acidente automobilístico. A maioria foi admitida em coma no hospital e não tinha lesões associadas além do TCE. Os óbitos foram uniformemente distribuídos ao longo do ano e o Hospital de Urgências de Sergipe foi responsável pela maioria dos atendimentos antes do óbito.

O índice de notificação $(1: 5,82)$, a taxa de aproveitamento das notificações (56,17\%), a taxa de notificação $(0,46 \mathrm{pmp} / \mathrm{ano})$ e a taxa de doação $(0,26$ pmp/ano) foram baixos.

Houve baixo aproveitamento do número de possíveis doadores de órgãos em Sergipe, de onde se pode inferir que há a necessidade de ações político-administrativas que incrementem as doações e transplantes no Estado.

\begin{abstract}
Transplant is the best treatment option for some terminal diseases in organs and the only option to interfere in the natural evolution of some kind of insufficiencies. Still, the main source of organs for transplantation is the corpse donor and this amount is not enough to attend the demand due to failures in many parts of the donation-transplant process. Purpose: To estimate the amount of possible organ and tissue donors in Sergipe; identify the profile of these possible donors; to calculate donation rates, notification and the reclamation of organ donors in this state. Methods: Quantitative, descriptive and retrospective research in which data gathered from the necropsy reports of the Forensic Institute of Sergipe and from the patient's charts reported in the state Transplant Center on the same period was used. Results: 1388 necropsy reports related to the deaths occurred from January 1st to December 31st 2007 were analyzed, from which 128 (9.22\%) possible donors were selected, being 108 (84.4\%) of the male gender. The average age was 30.95 years old and the uppermost age group was from 21 to 40 years old, represented by $54.4 \%$ persons. In the majority $(86 \%)$, victims were attended at the Emergency Hospital of Sergipe, which is the reference in trauma in this state, and the cause of the death in 78 cases (60.94\%), was traffic accident. In such period, there were 89 notifications to the Transplant Center, being 28 due to brain death. 50 donations were executed: 41 were strictly corneas, 8 corneas and kidneys and 1 of multiple organs. The notification index was 1:5.82; the utilization rate of notifications was $56.17 \%$; the notification rate was $0.46 \mathrm{pmp}$ and the donation rate $0.26 \mathrm{pmp}$. Conclusion: There was a low utilization in the amount of potential donors, and therefore, actions involving all society levels are necessary with the overall purpose to increase the amount of donations and transplants in Sergipe.
\end{abstract}

Keywords: Organ Donation; Transplants; Brain Injuries.

\section{REFERÊNCIAS}

1. PortFK, Wolfe RA, Mauger EA. Comparison of survival probabilities for dialysis patients vs. cadaveric renal transplant recipients. JAMA. 1993;(270):1339-43.

2. Schunuelle P, Lorenz D, Trede M, Van Der Woude FJ. Impact of cadaveric transplantation on survival in end-stage renal failure: evidence for reduced mortality risk compared with hemodialysis long-term follow-up. J Am Soc Nephrol. 1998;(9):2135-41.

3. Simmons RG, Abress L. Quality of life issues for end-stage renal diseases patients. Am. J. Kidney Dis. 1990;(15):201-8.

4. Wolfe RA, Ashby VB, Milford EL. Comparison of a mortality in all patients on dialisys, 
patients on dialisys awaiting transplantation and recipients of a first cadaveric transplant. N. Engl. J. Med. 1999;(341):1725-30.

5. Garcia VD. A política de transplantes no Brasil. Rev da AMRIGS. 2006;50(4):312-20.

6. Salomão A. Atualização em Transplante renal. J Bras Nephrol. 2000;(22):244-8.

7. Silva PR. Transplante cardíaco e cardiopulmonar: 100 anos de história e 40 de existência. Rev Bras Cir Cardiovasc. 2008;23(1):145-52.

8. Jatene AD, Stol NAG. História do Transplante cardíaco. Rev. Soc. Cardiol. 1995;(6):609-61.

9. Associação Brasileira de Transplantes de Órgãos. Registro brasileiro de transplante de órgãos, ano XV, nº, jan-dez-2009.<Disponível em http://www.abto.org.br> (acesso em 10/01/2010).

10. Pereira WA. Manual de Transplantes de Órgãos e Tecidos. 2 ed. Rio de Janeiro: Medsi; 2000.

11. Garcia VD, Abrahão MRC, Hoefelmann N. Procura de órgãos. In: Neumann J, Abbud Filho M, Garcia VD. Transplante de Órgãos e Tecidos. São Paulo: Sarvier. 1997; 91-102.

12. Matesanz R. Meeting the organ shortage: an European Consensus Document. Newsletter Transplant. 1999:(4):4-17.

13. Miranda B, Segovia C, Sanches M, Felipe C, Naya MT, Matesanz R. Evolution of organ procurement and donor characteristics in Spain. Transp. Proc. 1995;(27):2384-8.

14. Moraes EL, Massarollo MCKB. A recusa familiar para a doação de órgãos e tecidos para transplante. Rev Latino-am Enfermagem. 2008;16(3):458-64.

15. Cunha TR, Garrafa V, Machado AC, Portillo JAC. Filas para os transplantes de órgãos no Brasil: uma questão bioética. Disponível em <www.unesco.org.uy> (acesso em 15/03/2010).

16. BRASIL, Leis, etc. Lei n ${ }^{\circ} 9.434$ de fevereiro de 1997. Dispõe sobre a remoção de órgãos, tecidos e partes do corpo humano para fins de transplante e tratamento, e dá outras providências. Diário Oficial da União, Seção 1, Brasília, 5 fev. 1997.

17. BRASIL, Leis, etc. Decreto ${ }^{\circ} 2.268$ de 30 de junho de 1997. Regulamenta a Lei $n^{\circ} 9.434$ de 4 de fevereiro de 1997.Dispõe sobre a remoção de órgãos, tecidos e partes do corpo humano para fins de transplante e tratamento, e dá outras providências. Diário Oficial da União, Seção 1, Brasília, 1 jul. 1997.

18. Transplantes de órgãos no Brasil. Rev. Assoc. Med. Bras. 2003. 49. (1) [Editorial]. Disponível http://www.scielo.br/scielo.php (acesso em 10/05/2010).

19. Conselho Federal de Medicina. Resolução CFM n. ${ }^{\circ}$ 1480, de 08 de agosto de 1997. Define os critérios aplicados para o diagnóstico de morte encefálica no Brasil. Jornal do Conselho Federal de Medicina, p. 7, out. 1997.

20. BRASIL. Ministério da saúde: ações e programas /doação de órgãos. Disponível em www.saude.gov.br (acesso em 20/05/2010)

21. Sheehy E, Conrad SL, Brigham LE, Luskin R, Weber P, Eakin M et al. Estimating the number of potential organ donors in the United States. N Eng J Med. 2003;(349):667-74.

22. Matesanz R. Organización Nacional de Trasplantes: La consolidación de una estructura. Rev Esp Trasp. 1992;(1):81-4.

23. Marinho A. Um estudo sobre as filas para transplantes no Sistema Único de Saúde Brasileiro. Cad. Saúde Pública. 2006;22(10):2229-39.

24. Boni RC, Delmonte CA, Pestana JOM. Estimativa do número de potenciais doadores de órgãos na cidade de São Paulo em relação à situação do transplante de órgãos no Brasil. J Bras Transpl. 2002;(5):59-64.

25. Nogueira EC, Pereira CU. Potencial para obtenção de órgãos em um hospital de urgência de Sergipe. J Bras Transplant. 2007; (10): 756-61.

26. Alves-Júnior A, Cardoso ES, Figueiredo-Neto PB, Costa PSR, Sarasqueta DFO, Farias TWS et al. Estimativa de potenciais doadores de órgãos e tecidos no estado de Sergipe. J Bras Transpl. 2003;(6):208-10.

27. D’Imperio F. Morte encefálica, cuidados ao doador de órgãos e transplante de pulmão. Rev. Bras. Ter. Intensiva. 2007;19(1).

28. Rech TH, Rodrigues-Filho EM. Manuseio do potencial doador de múltiplos órgãos. Rev Bras Ter. intensiva. 2007;19 (2).

29. Fagioli FGD, Botoni FA. Tratamento do potencial doador de múltiplos órgãos. Rev. Med Minas Gerais. 2009;19(3):242-7.

30. Platt JL. Xenotransplantation: new risks, new gains. Nature. 2000;407:27.

31. Strom T. Stem cells: a replenishable source of cellular transplants. Proceedings of a Transplant Odyssey. 2001;23

32. Severino, AJ. Metodologia do Trabalho Científico. São Paulo: Cortez; 2002.

33. Schein AE, Carvalho PRA, Rocha TS, Guedes RR, Moschetti L; La Salvia JC et al. Avaliação do conhecimento de intensivistas sobre morte encefálica. Rev. Bras. Ter. Intensiva. 2008;20 (2).

34. Santos ALGA, Silva AAM, Santos RF. Estimativa do número potencial de doadores cadavéricos e da disponibilidade de órgãos e tecidos para transplantes em uma capital do nordeste do Brasil. J Bras Nefrol. 2006;28(1):25-30.

35. Morais M, Silva RCMA, Ramalho HJ, Silva RF, Abbud-Filho M. As Organizações de Procura de Órgãos (OPOs) são efetivas? Análise de sete anos de atividade de uma OPO brasileira. Arq Ciênc Saúde. 2004;11(4):225-9.

36. Darpon J, Arrieta J, Elorrieta P, Olaizola P, Lavari R, Aranzabal J. Evalution of a small organ procurement organization in the Basque Country. J Transpl. Coord. 1996;6(4):167-

37. Moraes EL, Silva LBB, Moraes TC, Paixão NCS, Izumi NMS, Guarino AJ. O perfil dos potenciais doadores de órgãos e tecidos. Rev Latino-am Enfermagem. 2009;17(5).

38. Moraes EL, Silva LBB, Glezer M, Paixão NCS, Moraes TC. Trauma e doação de órgãos e tecidos para transplante. J Bras Transpl. 2006;(9):561-5. 